\title{
Prospective Diary Study of Nonpainful and Painful Phantom Sensations in a Preselected Sample of Child and Adolescent Amputees Reporting Phantom Limbs
}

\author{
Krista L. Wilkins, RN, BScN, BSc(Hons), * Patrick J. McGrath, PhD, †f G. Allen Finley, MD, †ई and \\ Joel Katz, PhD"
}

Objective: To prospectively study factors associated with the occurrence of phantom sensations and pains in a pre-selected sample of child and adolescent amputees reporting phantom limbs.

Design: Prospective diary study over 1 month.

Participants:Fourteen child and adolescent amputees from 10-18 years of age who were missing a limb due to trauma $(n=12)$ or congenital limb deficiency $(n=2)$, and who had previously reported having phantom sensations and pain.

Main Outcome Measure: Diary used to assess the occurrence of non-painful and painful phantom sensations. Items included age, sex, location and cause of amputation, past experience with stump pain and pre-amputation pain, and intensity, quality, duration, and triggers of the sensations and pains.

Results: Thirteen amputees reported having 104 incidents of nonpainful phantom sensations with an average intensity of $4.17(\mathrm{SD}=$ 2.14 ) on a $0-10$ rating scale. Fifty-three incidents of phantom pain with an average intensity of $6.43(\mathrm{SD}=1.76)$ were recorded by 8 amputees. Both amputees with a congenital limb deficiency re-

From the *Department of Nursing, University of Manitoba, Winnipeg, Canada; †Pediatric Pain Research Lab, IWK Health Centre, Halifax, Nova Scotia, Canada; $\ddagger$ Departments of Psychology, Psychiatry, and Pediatrics, Dalhousie University, Halifax, Nova Scotia, Canada; §Department of Anaesthesia, IWK Health Centre, and Dalhousie University, Halifax, Nova Scotia, Canada; "Department of Psychology and School of Kinesiology and Health Science, York University, and Department of Anesthesia and Pain Management, Toronto General Hospital, Mount Sinai Hospital, and University of Toronto, Toronto, Ontario, Canada.

Supported by a grant from the IWK Health Centre awarded to Krista L. Wilkins. Patrick McGrath is supported by a Distinguished Scientist Award of the Canadian Institutes of Health Research (CIHR). Allen Finley is a Dalhousie University Clinical Research Scholar. Joel Katz is supported by a CIHR Canada Research Chair.

Reprints: Krista L. Wilkins, RN, BScN, BSc(Hons), Department of Nursing University of Manitoba, 1209-72 Donald Street, Winnipeg, Canada R3C IL7 (e-mail: umwilk04@cc.umanitoba.ca). ported phantom phenomena. Girls reported more psychosocial triggers than did boys whereas boys were more likely than girls to report that they could not identify a trigger $(P=0.0001)$. Boys also reported a higher proportion of physical triggers than psychosocial triggers while there were no differences for girls $(P=0.0001)$.

Discussion: Child and adolescent amputees experience phantom sensations and pains on a regular basis over a 1-month period. Differences in triggers of phantom phenomena between boys and girls may be due to differences in activities, awareness, attribution, and willingness to report psychosocial triggers.

Key Words: children, amputee, phantom sensation, phantom pain, prospective study

Non-painful and painful phantom limb sensations have been examined in adult amputees, but there is little research on child and adolescent amputees. ${ }^{1}$ Simmel $^{2}$ found that while phantom limbs are rare in amputees who have lost a limb before the age of 4 , the incidence of phantoms increases with the age at amputation and age at interview. More recently, Krane and Heller ${ }^{3}$ reported that $100 \%(24 / 24)$ of young amputees had phantom sensations and $83 \%$ (20/24) had phantom pain. In a field survey, we found that the loss of a limb due to surgery dramatically increased the likelihood of an amputee experiencing these phenomena. ${ }^{4}$ As well, amputees identified physical (eg, weather, wearing prosthesis) and psychosocial (eg, feeling nervous, objects approaching the stump) triggers of non-painful and painful phantom sensations. This survey, however, was retrospective and thus relied upon the amputees' memory.

Prospective research is needed to determine the frequency, quality, duration, and intensity of non-painful and painful phantom sensations in children experiencing these phenomena, thereby avoiding the potential biases and distortions of memory. In a prospective study of 142 adult amputees who kept a daily log of phantom pain, Arena and colleagues ${ }^{5}$ 
reported that phantom pain increased when amputees stood relatively still for prolonged periods or when the stump was subjected to sustained mechanical distortion resulting from heavy work or extensive walking over rough terrain. In another prospective study, Arena and colleagues ${ }^{6}$ followed 27 adult amputees who kept daily logs of phantom limb pain and stress for a 6 -month period. They found that 17 amputees (63\%) had same time increases in phantom pain and situational stress, 12 (44\%) had an increase in phantom pain which preceded an increase in stress, and 10 (37\%) had an increase in stress which preceded an increase in phantom pain. These 3 temporal relationships between pain and stress suggest different mechanisms may be at work to generate phantom limb pain. Particularly noteworthy from a psychologic perspective is the possibility that increased stress levels may precipitate episodes of phantom limb pain. ${ }^{1}$

More recently, Hill and colleagues ${ }^{7}$ conducted a prospective study of a single adult amputee to examine whether triggers could be identified for the somatosensory pain memories she reported, that is, the re-experience of pain in the phantom limb resembling her preoperative pain experience. ${ }^{8}$ Every day over a 9 -month interval, the amputee recorded her experience of ongoing phantom pain and the triggers of the pain. $A$ review of the pain records showed that the experience of the phantom pain memory was reliably associated with cognitive and emotional triggers.

The largest prospective diary study to date examined phantom limb pain and related factors through hourly pain diaries completed over a 1-week period. ${ }^{9}$ Eighty-nine lower limb adult amputees reported having 4-5 daily episodes of phantom limb pain, varying in intensity and lasting upwards to 6-10 hours. Amputees reported relying on such strategies as distraction, relaxation, seeking support, exercise, stump manipulation, and drugs and alcohol to cope with phantom limb pain. In assessing the role of activity in adjustment to phantom pain as a function of gender, the diaries indicated that women reported higher daily activity levels than men and this was correlated with higher pain scores.

Despite the increasing number of pain diary studies in the adult amputee population, there is only one prospective study that documents the nature of phantom sensations in an adolescent amputee who completed a brief sensation and pain $\log$ for 28 days immediately after surgery. ${ }^{10}$ However, we do not know whether her experiences are typical or atypical of adolescents who experience phantom sensations after amputation. ${ }^{10}$ Therefore, a prospective diary study was undertaken to provide a better description of the occurrence of nonpainful and painful phantom sensations in a group of child and adolescent amputees who experience them, and to assess the relative contributions of different stimuli or triggers in eliciting phantom sensations in a naturalistic setting. Differences between male and female amputees were also examined.

\section{MATERIALS AND METHODS}

\section{Participants}

Participants comprised a subset of amputees who took part in a previous study examining phantom limbs in child and adolescent amputees. ${ }^{4}$ An attempt was made to contact by telephone all 25 amputees from the original study sample who reported having nonpainful and painful phantom sensations. The telephone numbers of 2 amputees were no longer in service and therefore these 2 participants were not reached. Of the remaining 23 amputees, $19(76 \%)$ agreed to participate in the diary study. Fourteen of the 23 amputees provided complete data for a 1-month period. Of the four who did not finish the diary, one dropped out stating that the record keeping for the diary was too time consuming, and three never returned the diary despite numerous telephone reminders; and 1 set of diary data was unusable because the amputee did not follow directions properly.

The sample of 14 child and adolescent amputees ( 7 boys and 7 girls) who provided complete and usable data ranged in age from $10-18$ years (mean, $13.4 ; \mathrm{SD}, 2.4$ ). They were missing a limb because of a congenital limb deficiency $(n=2)$, cancer $(n=5)$, accident $(n=5)$, or other medical problems, such as gangrene $(n=2)$. There were 2 upper limb amputees (both below elbow) and 12 lower limb amputees (1 above knee, 6 below knee, 2 Syme's, and 3 Van Nes Rotation). The level of amputation for a Syme's amputation is through the ankle. For the Van Nes Rotation, "the leg is restructured so that the foot of the affected leg is placed at the level of the knee of the sound leg and the foot is turned 180 degrees. The foot then functions as a knee joint and in effect, the heel becomes the knee and the ankle joint becomes the knee joint."11 Participants, excluding the 2 with a congenital limb deficiency, had lost a limb on average $4.83(\mathrm{SD}=3.13)$ years earlier at the age of 8.33 years $(\mathrm{SD}=3.60)$. Table 1 highlights key participant variables including sex, side and level of amputation, reason for amputation, age at amputation and at diary completion, number of non-painful and painful phantom incidents, and the number of days they were reported over a 1-month period.

Without access to medical records, we were unable to determine whether the congenital absence of a limb was due to an accident in utero (eg, strangulation of a limb by the umbilical cord) or was a defect of embryological development.

\section{Procedure}

The participants and their parents were contacted by telephone and informed of the nature of the study. A consent form and diary along with a stamped, self-addressed return envelope were mailed to those willing to complete the diary for a 1-month period during the summer of 1997. A telephone call from the first author (K.W.) was made every week to each participant to resolve any questions they may have had, to problem solve, and to provide positive reinforcement and encour- 
TABLE 1. Key Variables Describing Participants, Including Sex, Side and Level of Amputation, Reason for Amputation, and Age at Amputation and at Diary Completion

\begin{tabular}{clllcccc}
\hline Participant & Sex & $\begin{array}{c}\text { Side and Level } \\
\text { of Amputation* }\end{array}$ & $\begin{array}{c}\text { Reason for } \\
\text { Amputation }\end{array}$ & $\begin{array}{c}\text { Age at } \\
\text { Amputation } \\
\text { (years) }\end{array}$ & $\begin{array}{c}\text { Age at Diary } \\
\text { Completion } \\
\text { (years) }\end{array}$ & $\begin{array}{c}\text { Nonpainful } \\
\text { Phantom Sensations } \\
\text { (\# Incidents/\# Days) }\end{array}$ & $\begin{array}{c}\text { Phantom Pain } \\
\text { (\# Incidents/\# Days) }\end{array}$ \\
\hline 1 & M & L-BK & accident & 6 & 10 & $12 / 12$ & $4 / 4$ \\
2 & M & L-BK & cancer & 10 & 14 & $8 / 8$ & $0 / 0$ \\
3 & F & L-BK & meningitis & 11 & 18 & $24 / 24$ & $10 / 10$ \\
4 & F & R-foot missing & congenital & N/A & 15 & $2 / 2$ & $2 / 2$ \\
5 & M & L-BK & accident & 9 & 11 & $2 / 2$ & $13 / 12$ \\
6 & F & L-AK & cancer & 4 & 14 & $0 / 0$ & $0 / 0$ \\
7 & F & R-BK & birth defect & 3 & 12 & $2 / 2$ & $0 / 0$ \\
8 & M & L-VNR & cancer & 12 & 16 & $1 / 1$ & $2 / 2$ \\
9 & M & L-BK & accident & 4 & 9 & $2 / 2$ & $1 / 1$ \\
10 & F & L-hand/arm missing & congenital & N/A & 14 & $2 / 2$ & $0 / 0$ \\
11 & F & R-VNR & cancer & 6 & 11 & $8 / 7$ & $0 / 0$ \\
12 & F & R-VNR & cancer & 11 & 11 & $8 / 5$ & $19 / 19$ \\
13 & M & R-S & accident & 6 & 14 & $4 / 4$ & $29 / 29$ \\
14 & M & L-BE & accident & 14 & 14 & 29 & 0
\end{tabular}

Also shown are the number of nonpainful and painful phantom incidents and the number of days they were reported over the 1-month period.

*Amputation described as left/right (L/R), and below/above knee (BK/AK), below elbow (BE). Symes (S), Van Nes Rotation (VNR). M, male; F, female.

agement. Younger amputees needed help to understand some of the descriptors of nonpainful and painful phantom sensations. For example, one amputee asked, "It's itchy then numb. Does that count?" In response to another amputee's concern about not having enough time to complete the diary, the suggestion of doing the diary as part of his bedtime routine worked. Participants received 20 dollars and a t-shirt upon completion of their diary. Approval for this study was obtained from the IWK Research Ethics Board.

\section{Measures}

Participants were instructed to complete the diary for each incident of non-painful phantom sensation and phantom pain over a 1-month period. Separate diary pages were included for sensations and pains. Background information including name, age, sex, province of residence, location of amputation, cause of amputation, previous stump pain, and preamputation pain was obtained. The diary also included items assessing the location, intensity, quality, duration, and triggers of the sensations and pains.

To describe the location of the sensations and pains, participants were asked to draw a line on a 2 dimensional figurine indicating the level of amputation and then to shade in the area where the sensations and pains occurred. Back and front views of the figurine were provided with labels indicating left and right. Because most participants indicated the level of amputation but did not shade in the area of the phantom in which the sensation or pain was experienced, this item was not included in the data analysis.
Intensity of the nonpainful phantom sensations and pain was rated on a $0-10$ scale with $0=$ no sensation (or pain) and $10=$ strongest imaginable sensation (or pain). A checklist of descriptors identified in a previous study ${ }^{4}$ was included on each page of the diary to detail the quality of the sensations and pains. The checklist consisted of 16 descriptors of non-painful phantom sensations (Table 2) and 32 descriptors of phantom pain (Table 3). Participants were asked to check as many or as few of the words that described each sensation or pain and to describe the duration of the phantom sensations and pains by checking seconds, minutes, hours, or days. Participants were also asked to recall any pain they may have felt just prior to amputation and to compare it to the current incident of phantom pain in location, strength, and quality. An open-ended item was used to assess the trigger(s) of the sensations and pain. Figure 1 shows a page from the pain diary of a participant in the study.

\section{Data Analyses}

Data were analyzed using the Statistical Package for the Social Sciences (SPSS for Windows, release 9.0, Chicago, IL) and Primer of Biostatistics ${ }^{12}$ (Version 4.0). Descriptive statistics were calculated to describe the participants, the number of incidents, and the median intensity of nonpainful phantom sensations and pains. Differences between the sexes were evaluated by independent samples $t$ test (age and intensity ratings of phantom incidents) and Mann-Whitney $U$ test (number of incidents). $x^{2}$ test was used to compare the sexes on the proportion of phantom incidents triggered by physical, psy- 
TABLE 2. Incidents of Nonpainful Phantom Sensations

\begin{tabular}{|c|c|c|c|}
\hline Descriptor & Frequency* & $\begin{array}{l}\text { Number of } \\
\text { Participants }\end{array}$ & $\begin{array}{c}\text { Median } \\
\text { (Minimum, } \\
\text { Maximum) } \\
\text { Frequency per } \\
\text { Participant }\end{array}$ \\
\hline Prickling & 61 & 5 & $10.0(4,21)$ \\
\hline Expanding & 15 & 2 & $7.5(1,14)$ \\
\hline Feels as if asleep & 54 & 6 & $5.5(1,23)$ \\
\hline Buzzing & 12 & 3 & $4.0(3,5)$ \\
\hline Fluttering & 7 & 2 & $3.5(1,6)$ \\
\hline Itchy & 22 & 5 & $3.0(2,9)$ \\
\hline Electric current & 17 & 5 & $3.0(1,7)$ \\
\hline Tingling & 54 & 11 & $2.0(1,22)$ \\
\hline Numb & 51 & 4 & $1.0(1,22)$ \\
\hline Tickling & 22 & 7 & $1.0(1,12)$ \\
\hline Swollen feeling & 17 & 4 & $1.0(1,14)$ \\
\hline Heaviness & 15 & 3 & $1.0(1,13)$ \\
\hline Feels very real & 2 & 2 & $1.0(1,1)$ \\
\hline Warm & 2 & 1 & 2.0 \\
\hline Wiggles & 1 & 1 & 1.0 \\
\hline $\begin{array}{l}\text { Taken apart and } \\
\text { put back together }\end{array}$ & 0 & & \\
\hline
\end{tabular}

*Frequency of descriptors exceeds the total number of incidents of nonpainful phantom sensations because participants were free to choose as many or as few of the words describing each incident.

chosocial, or unknown factors. Significant effects were followed up with subsequent 2 by $2 \chi^{2}$ tests using a multiple comparison procedure to determine the pattern of significance between the groups. ${ }^{12}$ In these instances, the Type I error rate was adjusted to $\alpha=0.01$ using Bonferroni's correction for multiple tests of significance (ie, $\alpha /$ number of tests). Otherwise, $P<0.05$ is considered statistically significant.

\section{RESULTS}

\section{Nonpainful Phantom Sensations}

Thirteen participants reported having a total of 104 incidents of nonpainful phantom sensations (median $=4.0$; range $=1-29$ ). Figure 2 shows the number of daily incidents of nonpainful and painful phantom sensations over the month-long study period. A high number of incidents were initially reported, followed by a relatively consistent but lower number of incidents. On average, the 104 incidents of nonpainful phantom sensations were rated a mean intensity of $4.17(\mathrm{SD}=2.14$; range $=1-10$ ).

Table 2 contains the complete list of descriptors for nonpainful phantom sensations showing the frequency with which each descriptor was endorsed, the number of participants reporting each descriptor, and the median, minimum, and maxi- mum frequencies. The 3 most common descriptors of nonpainful phantom sensations as measured by the median frequency per person were prickling (median $=10.0$ ), expanding (median $=7.5$ ), and feels as if asleep (median $=5.5$ ). In contrast, the 3 most common descriptors as reported by the greatest number of participants were tingling $(n=11)$, tickling $(n=7)$, and feels as if asleep $(n=6)$.

Nonpainful phantom sensations lasted seconds for 31 incidents $(n=9)$, minutes for 21 incidents $(n=9)$, and all day for 52 incidents $(n=2)$. Fifteen incidents $(n=5)$ began in the

\begin{tabular}{|c|c|c|c|}
\hline Descriptor & Frequency* & $\begin{array}{l}\text { Number of } \\
\text { Participants }\end{array}$ & $\begin{array}{c}\text { Median } \\
\text { (Minimum, } \\
\text { Maximum) } \\
\text { Frequency per } \\
\text { Participant }\end{array}$ \\
\hline Tingly & 23 & 3 & $9.0(2,12)$ \\
\hline Throbbing & 19 & 3 & $7.0(3,9)$ \\
\hline Piercing & 6 & 1 & 6.0 \\
\hline Pricking & 16 & 3 & $5.0(2,9)$ \\
\hline Pins and needles & 9 & 2 & $4.5(2,7)$ \\
\hline Hot & 9 & 2 & $4.5(1,8)$ \\
\hline Shooting & 11 & 3 & $4.0(2,5)$ \\
\hline Spasms & 16 & 4 & $3.0(1,9)$ \\
\hline Aching & 16 & 6 & $2.5(1,5)$ \\
\hline Sore & 9 & 5 & $2.0(1,2)$ \\
\hline Pinching & 7 & 3 & $2.0(1,4)$ \\
\hline Knife jabs & 4 & 2 & $2.0(1,3)$ \\
\hline Pulling & 2 & 1 & 2.0 \\
\hline Uncomfortable & 23 & 6 & $1.5(1,9)$ \\
\hline Dull & 13 & 4 & $1.5(1,9)$ \\
\hline Squeezing & 6 & 4 & $1.5(1,2)$ \\
\hline Twisting & 3 & 2 & $1.5(1,2)$ \\
\hline Sharp & 13 & 5 & $1.0(1,5)$ \\
\hline Unbearable & 12 & 3 & $1.0(1,10)$ \\
\hline Tight & 9 & 4 & $1.0(1,6)$ \\
\hline Stinging & 5 & 4 & $1.0(1,2)$ \\
\hline Electric current & 3 & 3 & $1.0(1,1)$ \\
\hline Stretching & 3 & 3 & $1.0(1,1)$ \\
\hline Cool & 2 & 2 & $1.0(1,1)$ \\
\hline Burning sensation & 2 & 2 & $1.0(1,1)$ \\
\hline Smashed & 1 & 1 & 1.0 \\
\hline Bad cramps & 1 & 1 & 1.0 \\
\hline Steaming & 1 & 1 & 1.0 \\
\hline Warm & 1 & 1 & 1.0 \\
\hline Crushing & 0 & & \\
\hline Screaming & 0 & & \\
\hline
\end{tabular}

*Frequency of descriptors exceeds the total number of incidents of painful phantom sensations because participants were free to choose as many or as few of the words describing each incident. 


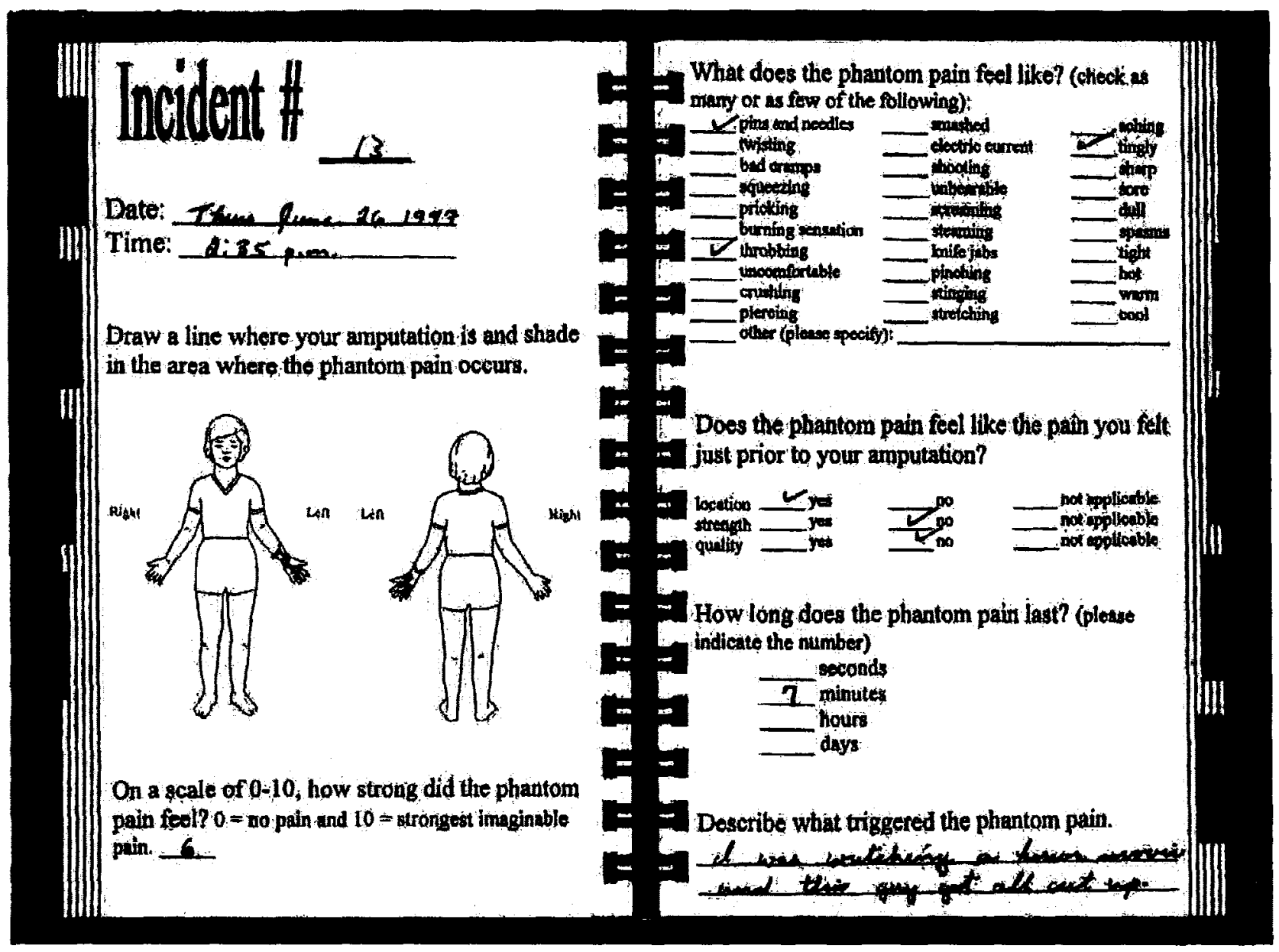

FIGURE 1. Sample diary entry for Participant 14 describing an incident of phantom limb pain showing location, intensity, and duration of pain, descriptors selected, similarity to preamputation pain, and triggering event.

"AM hours" and $65(\mathrm{n}=12)$ began during the "PM hours." One participant did not specify the time at which the sensations began for 24 incidents. Psychosocial stimuli (eg, meeting someone for the first time, watching a gruesome scene in a movie) triggered 37 incidents, and physical stimuli (eg, bathing) triggered 34 incidents. Participants were not sure what triggered 34 incidents. Table 4 lists examples of stimuli that triggered non-painful phantom sensations.

\section{Phantom Limb Pain}

Eight participants reported having a total of 53 incidents of painful phantom sensations (median $=3.0$; range $=1-19$ ). All participants had stump pain and 5 participants had preamputation pain. Seven of the 8 participants that reported painful phantom sensations also reported having non-painful phantom sensations during the 1 -month period. The participant experiencing painful phantom sensations but no non-painful phantom sensations reported having both sensations and pains during the winter rather than during the summer.

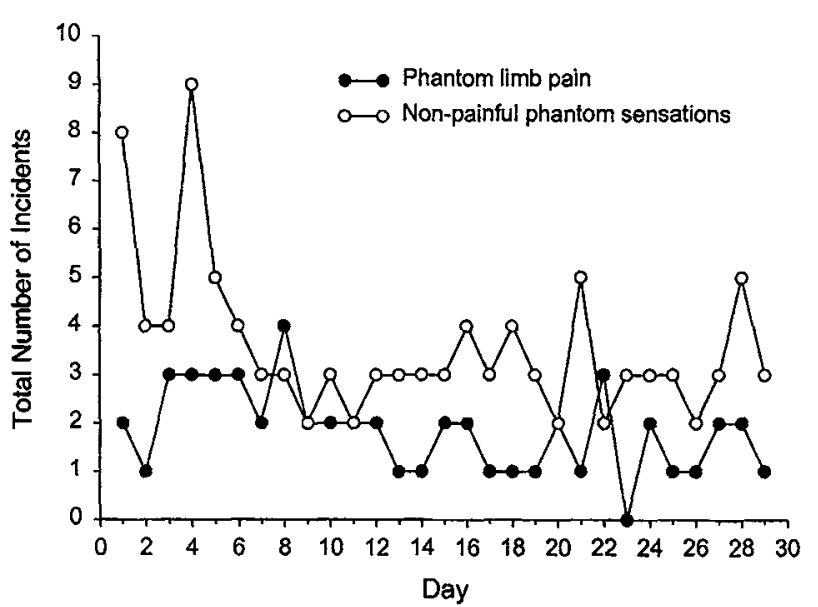

FIGURE 2. Total daily number of incidents of non-painful phantom sensations and phantom pain over the 1-month period of diary recording. 
TABLE 4. Reported Triggers of the Incidents of Nonpainful Phantom Sensations

\begin{tabular}{|c|c|c|c|}
\hline Trigger & Frequency & $\begin{array}{l}\text { Number of } \\
\text { Participants }\end{array}$ & $\begin{array}{c}\text { Median } \\
\text { (Minimum, } \\
\text { Maximum) } \\
\text { Frequency } \\
\text { per } \\
\text { Participant }\end{array}$ \\
\hline $\begin{array}{l}\text { Psychosocial } \\
\text { Doing nothing } \\
\text { Day dreaming about } \\
\text { Witnessing accident } \\
\text { Thinking about stump } \\
\text { Doing homework } \\
\text { Watching TV } \\
\text { Reading a book }\end{array}$ & 37 & 6 & $2.5(1,24)$ \\
\hline $\begin{array}{l}\text { Physical } \\
\text { Scratching stump } \\
\text { incision } \\
\text { Not wearing }\end{array}$ & 33 & 10 & $2.0(1,10)$ \\
\hline $\begin{array}{l}\text { prosthesis } \\
\text { Tired }\end{array}$ & & & \\
\hline $\begin{array}{l}\text { Swimming } \\
\text { Playing football or } \\
\text { soccer }\end{array}$ & & & \\
\hline $\begin{array}{l}\text { Sitting for long time } \\
\text { Gardening } \\
\text { Working on farm } \\
\text { Hiking } \\
\text { Walking } \\
\text { Bathing } \\
\text { Standing } \\
\text { Being cold }\end{array}$ & & & \\
\hline Cold not identify trigger & 34 & 6 & $2.0(1,28)$ \\
\hline
\end{tabular}

On average, the 53 incidents of phantom pain were rated a mean intensity of $6.43(\mathrm{SD}=1.76$; range $=3-10)$. The 3 most common descriptors of phantom pain as a function of median frequency per person were tingling (9.0), throbbing (7.0), and piercing (6.0). Descriptors chosen by the greatest number of participants included aching $(n=6)$, uncomfortable $(n=6)$ and sore $(n=5)$. Table 3 shows a complete list of descriptors of phantom pain.

Phantom pain lasted seconds for 25 incidents $(n=4)$, minutes for 24 incidents $(n=7)$, hours for 3 incidents $(n=2)$, and all day for 1 incident $(n=1)$. Phantom pain began during the "AM hours" for 11 incidents $(n=5)$ and during the "PM hours" for 42 incidents $(n=8)$. Physical stimuli triggered 33 incidents of phantom pain, and psychosocial stimuli triggered 6 incidents. Participants could not identify triggers for 17 incidents. Table 5 lists examples of stimuli that triggered phantom pain.
Of the 5 participants who reported having had preamputation pain, 2 indicated a similarity between the phantom limb pain and the preamputation pain. Both participants indicated similarities in location for 21 incidents, and 1 indicated that his phantom pain was similar in strength for 2 incidents and in quality for 1 incident.

\section{Congenital Limb Deficiency}

The 2 participants with congenital absence of a limb each reported 2 incidents of nonpainful phantom sensations and 2 incidents of pain over the 1-month recording period (Table 1). The incidents of nonpainful sensations ranged in intensity from 5 to 10 , lasted several minutes, and were described as "swollen" and "expanding" (Participant 10), as well as the usual paresthetic sensations of "tingling," numb," and "feels as if asleep" (Participant 4). The incidents of phantom pain were reported to be on the high end of the scale, ranging in

TABLE 5. Reported Triggers of the Incidents of Painful Phantom Sensations

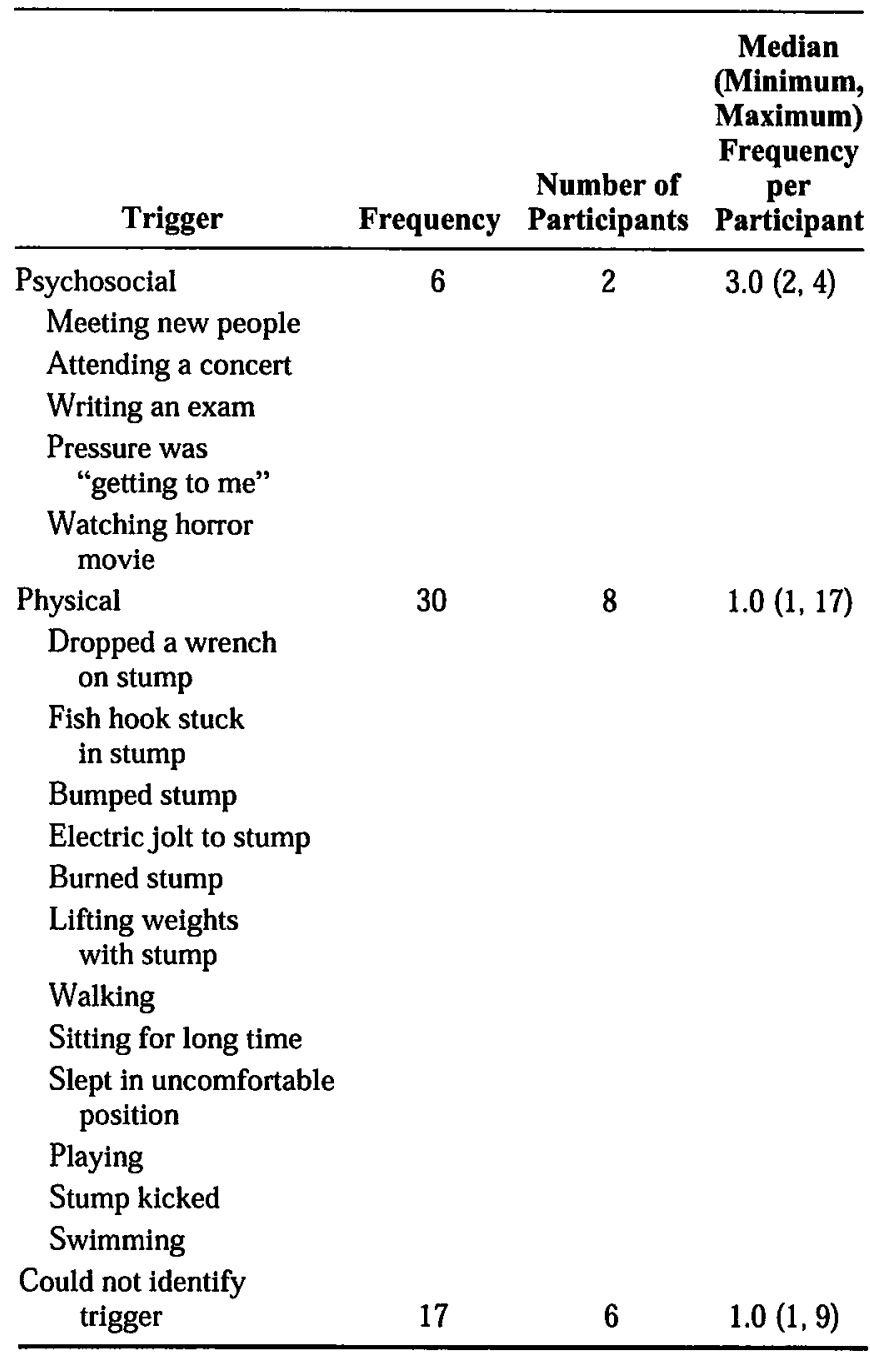


intensity from 7 to 10 , lasting up to 5 minutes in duration, and were described variously as "aching," "unbearable," "squeezing," and "sharp." There were no features that we could discern from the reports of these participants that distinguished them from the surgical amputees.

\section{Sex Differences in Phantom Pain and Nonpainful Phantom Sensations}

Girls and boys did not differ significantly in the mean age at amputation or diary completion, the median number of incidents, or in the mean intensity of phantom sensations or pain reported over the 1-month period (Table 6). However, there was a significant sex difference in the nature of the factors that were reported to trigger phantom sensations and pains $\left(\chi^{2}(2)=20.9, P=0.0001\right)$. Specifically, boys reported a significantly lower proportion of psychosocial triggers than physical triggers whereas there was no difference for girls $\left(\chi^{2}(1)=15.0, P=0.0001\right)$. In addition, girls reported a significantly greater proportion of psychosocial triggers than did boys whereas boys were significantly more likely than girls to report that they could not identify a trigger $\left(\chi^{2}(1)=14.5\right.$, $P=0.0001$ ). This was not the case for incidents identified as being triggered by physical factors; boys and girls did not differ significantly in the proportion of incidents for which they could not identify a trigger versus incidents reported to be triggered by physical factors $\left(\chi^{2}(1)=0.004, P=0.95\right)$.

\section{DISCUSSION}

The results of the present study demonstrate that child and adolescent amputees, like their adult counterparts, experience phantom limb sensations and pain on a regular basis

TABLE 6. Sex Differences in Age, Number of Incidents, Intensity, and Triggers of Phantom Sensations and Pain

\begin{tabular}{lrrr}
\hline \multicolumn{1}{c}{ Variable } & $\begin{array}{c}\text { Boys } \\
(\mathbf{n}=7)\end{array}$ & $\begin{array}{c}\text { Girls } \\
(\mathbf{n}=7)\end{array}$ & \multicolumn{1}{c}{$\boldsymbol{P}$} \\
\hline Mean age in years (SD) & & & \\
$\quad$ At amputation & $12.6(2.6)$ & $* 13.6(2.5)$ & 0.48 \\
$\quad$ At diary completion & $8.7(3.6)$ & $7.0(3.8)$ & 0.12 \\
Median (min, max) \# of incidents & & & \\
$\quad$ Phantom sensations & $4(1,29)$ & $5(2,24)$ & 1.0 \\
$\quad$ Phantom pain & $4(2,19)$ & $2(1,13)$ & 0.44 \\
Mean intensity (SD) & & & \\
$\quad$ Phantom sensations & $4.2(2.0)$ & $4.1(2.3)$ & 0.33 \\
$\quad$ Phantom pain & $5.9(1.8)$ & $6.8(1.6)$ & 0.98 \\
Type of trigger (total incidents) & & & \\
$\quad$ Physical & 40 & 23 & 0.0001 \\
Psychosocial & 10 & 33 & \\
Could not identify & 33 & 18 & \\
\hline
\end{tabular}

*Two participants with congenital limb deficiency not included. over a 1-month period. It should be noted that the sample of participants in the present study was selected from an earlier study ${ }^{4}$ based on the prior report of phantom pain or nonpainful phantom sensations. Thus, the results of the present study cannot address the issue of phantom limb pain incidence or prevalence.

The intensity of nonpainful phantom sensations and pain reported by the amputees were moderately high (averaging 4 and 6 respectively on $0-10$ scale). Fortunately, the incidents were generally short in duration and most occurred only once a day. This is further evidence that both adult and pediatric amputees experience discrete episodes rather than constant nonpainful and painful sensations. ${ }^{9.10}$ Participants initially reported a higher number of incidents of both painful and nonpainful phantom sensations per day, followed by a relatively consistent but lower number of incidents reported over time. This pattern may reflect a more general phenomenon of a spike in symptom reporting that occurs when people first begin selfmonitoring.

Overall, it appears that the most frequent descriptions of nonpainful phantom sensations are fairly similar for children, adolescents, and adults. We calculated the most common descriptors of phantom limb phenomena reported by the present sample using a within and a between subjects approach (Tables 2 and 4). With the exception of "expanding," both methods indicated that the most common descriptors of nonpainful phantom limb sensations (eg, "prickling," "as if asleep," "tingling," "tickling") were sensory-discriminative in nature and characteristic of the nonpainful paresthesias typically reported by the majority of adult amputees. ${ }^{10,13,14}$ Thus, child, adolescent, and adult amputees report experiencing similar qualities of nonpainful phantom limb sensation at least with respect to the most frequent of these sensations.

There appears to be less agreement when it comes to the most common descriptions of phantom limb pain. This seems to be true for the descriptors (1) chosen within and between subjects in the present sample as well as (2) from the adult amputee literature describing phantom pain. In the present sample, the most common words for phantom limb pain were "tingling," "throbbing," "piercing," "aching," "uncomfortable," and "sore." The adult amputee literature is equally variable. Jensen and colleagues ${ }^{13}$ found that the most frequent words used to describe phantom pain were "squeezing" and "burning," whereas Sherman et al ${ }^{15}$ found the words "shooting," "squeeze," "hot," and "cramp" were used most frequently by their sample to describe the various qualities of phantom limb pain. The greater variability in the most common descriptors of phantom limb pain versus nonpainful phantom limb sensations reported by child, adolescent, and adult amputees is not surprising and likely reflects the multiple mechanisms responsible for this disorder.

The findings from the 2 participants with congenital limb deficiency who each reported phantom phenomena are 
particularly interesting since they contribute to the ongoing debate about the origin of the body schema and to the issue of the neuroplasticity of the developing nervous system. The present results are consistent with evidence that phantom limbs are reported by individuals with congenital absence of limbs ${ }^{16-18}$ and they provide some of the strongest data to support the suggestion that the phantom limb represents a perceptual correlate of an innate, neural substrate of the body experience. $^{19}$

On the surface, these findings appear at odds with current views on the capacity of the developing nervous system to reorganize. ${ }^{20}$ The absence of an intact limb from birth followed by years of use-dependent sensori-motor experience with the residual appendage might be expected to result in a takeover of brain regions subserving the absent limb by nearby structures $^{21}$ and the absence of phantom experiences. While persons with congenital limb deficiency who do not report phantom pain or other sensations do not differ in the extent of cortical organization as measured by neuromagnetic source imaging from traumatic amputees, ${ }^{22}$ there are no similar investigations on congenital amputees, such as those in the present study who do report phantom pain and phantom sensations. Nevertheless, the present findings indicate that the 2 adolescents with congenital limb deficiency continue to report phantom limb phenomena in spite of extensive opportunity over the years for subcortical and cortical reorganization to occur. Perhaps it is precisely because of the plasticity associated with the developing nervous system that allows for the continued experience of phantom limbs in these individuals. It should be noted, however, that this is a select sample of 2 adolescents with a congenital limb deficiency and their reports are not necessarily representative of congenital amputees as a whole.

The majority of the factors that participants identified as triggering phantom pains and sensations were either physical or psychosocial in nature. This is consistent with previous reports that these phenomena can be triggered in psychologically healthy adult amputees by psychologic and emotional factors, ${ }^{7,8,23,24}$ as well as stimulation of the stump ${ }^{5,15,25}$ and other body regions. ${ }^{26}$ Participants could not identify triggers for approximately one-third of the reported incidents and just under half of the participants reported at least 1 incident for which they were unable to identify a trigger. Taken together, these results confirm recent suggestions that phantom limb phenomena may be triggered by a variety of factors, both peripheral and central, due to a convergence and summation of inputs in brain regions involved in cognitive and emotional processes. ${ }^{14.27}$

Thirty-seven percent of phantom sensations and 11 percent of phantom pains were triggered by psychosocial stimuli that appeared, in many instances, to involve stressful, anxietyarousing events. For example, participants reported pain in response to viewing emotionally disturbing events (watching a horror film, witnessing an accident). Others have documented that similar situations involving mental stress and anxiety provoke transient increases in the intensity of phantom limb sensations and pain. ${ }^{1,6,28}$ These very same states also induce reflex bursting activity in cutaneous sudomotor and vasomotor sympathetic fibers. ${ }^{29,30}$ Moreover, distraction, attention diversion, and intense concentration, which reduce phantom limb pain, ${ }^{23,24}$ also diminish peripheral sympathetic nervous system activity. ${ }^{30}$ Taken together, these results provide support for a model of phantom limb pain involving a sympathetic-efferent, somatic afferent cycle of activity and they suggest that relaxation training and other cognitive strategies directed at anxiety reduction and increasing self control may be effective in reducing phantom limb pain at least among certain amputees. ${ }^{1}$ For example, the finding that $76 \%$ of childhood amputees reported being able to decrease the phantom pain by ignoring it ${ }^{4}$ suggests that they were using adaptive cognitive coping strategies and that they may be amenable to other cognitivebehavioral interventions for pain management. Further study of the psychosocial and physiological risk factors associated with the development of phantom limb pain is warranted given the predictions of the model described above and the recent empirical and theoretical emphases on fear of pain and related constructs such as anxiety sensitivity. ${ }^{31-34}$

Although sex and gender differences in phantom limb experience have been investigated (with equivocal results) in the adult amputee population, ${ }^{9,35,36}$ to the best of our knowledge, this is the first study to show such differences between boy and girl amputees. Girls and boys differed in terms of the nature of the triggers they identified for the incidents of phantom limb sensations and pain but not in the mean number or intensity of incidents. Girls reported a significantly greater proportion of psychosocial triggers than did boys while boys were significantly more likely to be uncertain about what triggered an incident. In addition, boys reported a significantly greater proportion of physical triggers than did girls. This pattern of results raises a number of possibilities that deserve further study. We do not know to what extent this pattern of results represents a difference between boys and girls in (1) the nature of activities (eg, physical vs. social) engaged in, (2) awareness of psychosocial triggers, (3) attribution of phantom incidents to psychosocial triggers, (4) willingness to report psychosocial triggers, or (5) some combination of these possibilities. There are no data on how these triggers of phantom pain and sensations are distributed in adult men and women amputees. Further research should examine these possibilities, noting whether the gender difference is similar in the adult amputee population.

Despite documentation of the qualitative and quantitative qualities of phantom limbs, there are limitations to the present study. For one, diary completion is a time consuming and complex process, especially for young children and adolescents, thereby increasing the likelihood of nonadherence. Although we were in telephone contact with each participant 
on a weekly basis, we do not know how adherent participants actually were with the diary completion process. It is unlikely that they recorded every incident and therefore, the results may be a conservative estimate of the true frequency and intensity of phantom limb sensations and pain in these participants. Second, the study was conducted over the summer months, and to the extent that weather influences phantom limb pain, ${ }^{3.4}$ the present results may reflect a seasonal effect. Third, the sex differences in reporting of triggers may be due to a reporting bias. In addition, the trigger data were collected using an openended response format instead of item selection. Finally, since we did not assess to what extent participants were disabled by the pain or how much it interfered with their everyday activities, we cannot comment on the magnitude of the problem in children and adolescent amputees.

For maximum therapeutic benefits, the specific characteristics distinguishing subgroups of amputees experiencing phantom limbs needs to be examined. As well, further investigation is required to determine what strategies this population uses to cope with nonpainful and painful phantom sensations and the success of such strategies. Future research may be directed at inducing nonpainful and painful phantom sensations in a laboratory situation to better understand the underlying psychologic and psychophysiological processes.

\section{ACKNOWLEDGMENT}

The authors are indebted to the participants who kindly participated in the study.

\section{REFERENCES}

1. Katz J, Gagliese L. Phantom limb pain: a continuing puzzle. In: Gatchel RJ, Turk DC, eds. Psychosocial Factors in Pain. New York: Guilford Press; 1999:284-300.

2. Simmel ML. Phantom experiences following amputation in childhood. JNeurol Neurosurg Psychiatry. 1962;25:69-78.

3. Krane EJ, Heller LB. The prevalence of phantom sensation and pain in pediatric amputees. J Pain Symptom Manage. 1995;10:21-29.

4. Wilkins KL, McGrath PJ, Finley GA, et al. Phantom limb sensations and phantom limb pain in child and adolescent amputees. Pain. 1998;78:7-12.

5. Arena JG, Sherman RA, Bruno GM. The relationship involving humidity level, temperature, and phantom limb pain: preliminary analysis. Biofeedback Self Regul. 1989;14:128.

6. Arena JG, Sherman RA, Bruno GM, et al. The relationship between situational stress and phantom limb pain: cross-lagged correlational data from six month pain logs. J Psychosom Res. 1990;34:71-77.

7. Hill A, Niven CA, Knussen C. Pain memories in phantom limbs: a case study. Pain. 1996;66:381-384

8. Katz J, Melzack R. Pain "memories" in phantom limbs: review and clinical observations. Pain. 1990;43:319-336.

9. Whyte AS, Niven CA. Variation in phantom limb pain: results of a diary study. J Pain Symptom Manage. 2001;22:947-953.

10. McGrath PA. Hillier, LM. Phantom limb sensations in adolescents: a case study to illustrate the utllity of sensation and pain logs in pediatric clinical practice. J Pain Symptom Manage. 1992;7:46-53.
11. War Amputations of Canada. Amputation. Ottawa, Ontario: War Amputations of Canada; 1995:47.

12. Glantz SA. Primer of Biostatistics: The Program. New York, McGrawHill; 1997.

13. Jensen TS, Krebs B, Neilsen J, et al. Phantom limb, phantom pain and stump pain in amputees during the first 6 months following limb amputation. Pain. 1983;17:243-256.

14. Katz J. Psychophysical correlates of phantom limb experience. J Neurol Neurosurg Psychiatry. 1992;55:811-821.

15. Sherman RA, Sherman CJ, Parker L. Chronic phantom and stump pain among American veterans: results of a survey. Pain. 1984;18:83-95.

16. Vetter RJ, Weinstein $S$. The history of the phantom in congenitally absent limbs. Neuropsychologia. 1967;5:335-338.

17. Weinstein S, Sersen EA. Phantoms in cases of congenital absence of limbs. Neurology. 1961;11:906-911.

18. Melzack R, Israel $R$, Lacroix $R$, et al. Phantom limbs in people with congenital limb deficiency or amputation in early childhood. Brain. 1997; 120:1603-1620.

19. Melzack R. Phantom limbs, the self, and the brain (The D.O. Hebb memorial lecture). Can Psychol. 1989;30:1-16.

20. Porter FL, Grunau RE, Anand KJ. Long-term effects of pain in infants. J Dev Behav Pediatr. 1999;20:253-261.

21. Skoyles JR. Is there a genetic component to body schema? Trends Neurosci. 1990;13:409.

22. Flor H, Elbert T, Muhlnickel W, et al. Cortical reorganization and phantom phenomena in congenital and traumatic upper-extremity amputees. Exp Brain Res. 1998;119:205-212.

23. Morgenstern FS. The effects of sensory input and concentration on postamputation phantom limb pain. J Neurol Neurosurg Psychlatry. 1964;27: 58-65.

24. Parkes $\mathrm{CM}$. Factors determining the persistence of phantom pain in the amputee. J Psychosom Res. 1973;17:97-108.

25. Carlen PL, Wall PD, Nadvorna H, et al. Phantom limbs and related phenomena in recent traumatic amputations. Neurology. 1978;28:211-217.

26. Katz J, Melzack R. Referred sensations in chronic pain patients. Pain. 1987;28:51-59.

27. Katz J. Psychophysiological contributions to phantom limbs. Can JPsychiatry. 1992;37:282-298.

28. Pilowsky I, Kaufman A. An experimental study of atypical phantom pain. BrJPsychiatry. 1965;111:1185-1187.

29. Delius $\mathrm{W}$, Hagbarth $\mathrm{KE}$, Hongell $\mathrm{A}$, et al. Manoeuvres affecting sympathetic outflow in human muscle nerves. Acta Physiol Scand. 1972;84: 82-94.

30. Hagbarth KE, Hallin RG, Hongell A, et al. General characteristics of sympathetic activity in human skin nerves. Acta Physiol Scand. 1972;84:164176.

31. Muris $P$, Vlaeyen J, Meesters $C$. The relationship between anxiety sensitivity and fear of pain in healthy adolescents. Behav Res Ther, 2001;39: $1357-1368$.

32. Muris P, Vlaeyen JW, Meesters $C$, et al. Anxiety sensitivity and fear of pain in children. Percept Mot Skills. 2001;92:456-458.

33. Asmundson GJ, Norton PJ, Norton GR. Beyond pain: the role of fear and avoidance in chronicity. Clin Psychol Rev. 1999;19:97-119.

34. Kooijman CM, Dijkstra PU, Geertzen JH, et al. Phantom pain and phantom sensations in upper limb amputees: an epidemiological study. Pain. 2000;87:33-41.

35. Weiss SA, Lindell B. Phantom limb pain and etiology of amputation in unilateral lower extremity amputees. J Pain Symptom Manage. 1996;11: 3-17.

36. Jensen TS, Krebs B, Nielsen J, et al. Immediate and long-term phantom pain in amputees: incidence, clinical characteristics and relationship to pre-amputation pain. Pain. 1985;21:268-278. 